\title{
Cracking in a Cristobalite-Containing Mullite Body during Cooling
}

\author{
Takashi SATO, Yoshinari SAWABE, * Yutaka OHYA, ${ }^{* *}$ Mikio SUGAI and Zenbe-e NAKAGAWA \\ Faculty of Engineering and Resource Science, Akita University, 1-1. Tegata Gakuen-cho, Akita-shi 010-8502 \\ *Tsukuba Research Laboratory, Sumitomo Chemical Co., Ltd., 6, Kitahara, Tsukuba-shi, Ibaraki 300-3294 \\ **Faculty of Engineering, Gifu University, 1-1, Yanagido, Gifu-shi 501-1112
}

\author{
クリストバライト含有ムライト焼成体の冷却中に発生する亀裂の発生機構 \\ 佐藤 隆・沢辺佳成*。大矢 豊**。管井幹夫。中川善兵衛 \\ 秋田大学工学資源学部, 010-8502 秋田市手形学園町 1-1 \\ *住友化学工業(株)筑波研究所, 300-3294 つくば市北原 6 \\ **岐阜大学工学部, 501-1112 岐阜市柳戸 1-1
}

\begin{abstract}
Cracking of a cristobalite-containing mullite body at the middle stage of crystallization during cooling was investigated by acoustic emission (AE) and the crack formation was discussed. The specimen was composed of an outside layer of crystalline cristobalite and the inner part remaining as a glass phase. There are two kinds of cracks, of which the one is almost parallel to the surface of specimen at the boundary between the outside layer and the inner part and the other is perpendicular to the surface. AE signals indicated that the cracks occurred in two stages, the first stage at the temperature range $750-650^{\circ} \mathrm{C}$ and the second stage below $250^{\circ} \mathrm{C}$. Cracks parallel to the surface were formed at the first stage due to a mismatch in thermal expansion coefficient between the outside layer and the imner part. Those perpendicular to the surface were generated at the second stage under a tensile stress developed in the outside layer, which was caused by the $\beta-\alpha$ phase transition of cristobalite, in the direction parallel to the surface
\end{abstract}

[Received September 13, 1999; Accepted January 18, 2000]

Key-words: Cristobalite-containing mullite, Cracking, Acoustic emission, Thermal stress, $\beta$ - $\alpha$ phase transition of cristobalite

\section{Introduction}

Mullite ceramics are expected to be a candidate for the engineering materials to be used at high temperatures. As they are not easy to be sintered, it is necessary to heat the samples above the eutectic temperature $\left(1587 \pm 10^{\circ} \mathrm{C}\right)$ of $\mathrm{SiO}_{2}-\mathrm{Al}_{2} \mathrm{O}_{3}$ system in order to obtain dense bodies by the conventional sintering methods. The sintered bodies above the eutectic temperature usually contain glass as an intergranular phase. The glass phase, however, degrades the own superior mechanical properties of mullite crystal at high temperatures, ${ }^{1-4)}$ though it promotes the sintering of mullite ceramics.

The authors attempted to crystallize the glass phase contained in the ceramics by heating below the eutectic temperature and to prepare mullite ceramics having superior high-temperature mechanical properties. In the previous paper, ${ }^{5}$ ) we reported the crystallization behavior of glass phase in mullite ceramics having excess silica composition more than the stoichiometric by reheating at $1500^{\circ} \mathrm{C}$ and explained the crystallization to cristobalite as a surface crystallization mechanism. In that study, the microstructure observation visualized some large cracks in the cross section of specimens at the middle stages of crystallization, except the specimens reheated for a long time and crystallized completely. Examples of micrographs are shown in Fig. 1. The directions of crack propagation are classified into two groups. One is the group of cracks being almost parallel to the surface of specimen at the boundary between the crystalline and glass phases. The other is the group of cracks which is perpendicular to the surface of specimen, joining the former cracks to the surface. Since these cracks cause a fatal fault for engineering ceramic properties, it is necessary to clarify their formation and to control the microstructure in order to suppress their occurrence.

There are two supposed factors of the crack formation for cristobalite-containing mullite ceramics considered in this research. The first is $\beta-\alpha$ phase transition of cristobalite $^{6)}$ at the temperature range of $267-227^{\circ} \mathrm{C}$ during cooling process, which is accompanied with a large volume contraction. The second is based on a mismatch of thermal expansion coefficient in the composite material composed of the outside mullite-cristobalite layer and the inside mullite-glass layer, resulting from the surface crystallization of cristobalite.

The authors ${ }^{7)}$ have examined the crack occurrence in a porcelain body during cooling by acoustic emission (AE)

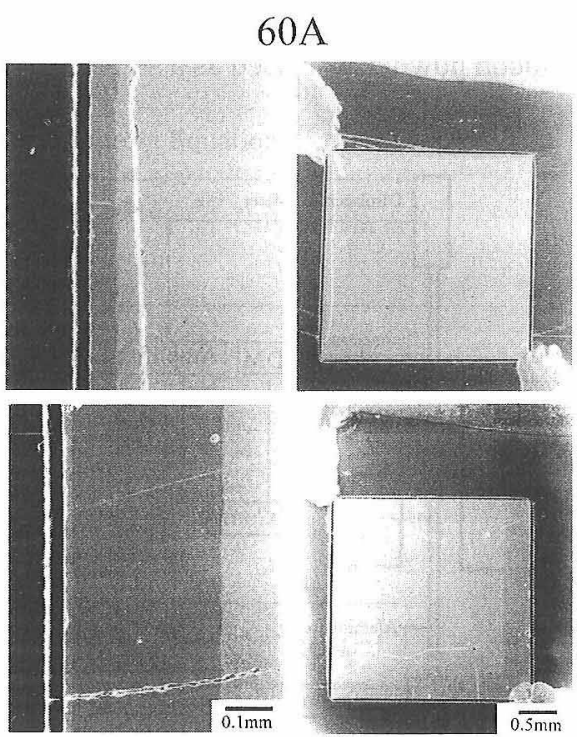

Fig. 1. SEM photographs of cross-section of $60 \mathrm{~A}$-specimens reheated at $1500^{\circ} \mathrm{C}$ for (1) $4 \mathrm{~h}$, (2) $24 \mathrm{~h}$ 
and showed that the cracking occurred in a temperature range of $900-800^{\circ} \mathrm{C}$ higher than the temperature of $\beta-\alpha$ phase transition of quartz $\left(573^{\circ} \mathrm{C}\right)$. In this work, we examined the cracking of cristobalite-containing mullite ceramics during cooling by $\mathrm{AE}$ and discussed the crack formation.

\section{Experimental procedure}

2.1 Measurements of $A E$ and thermal contraction

The measurement apparatus of AE used in this work is shown in Fig. 2. An alumina sample stage on an alumina rod was set in a vertical type electric furnace with $\mathrm{SiC}$ heater. An AE sensor was fixed at the bottom of alumina rod and detected the acoustic emission from the specimen. The specimen was placed in a dilatometer that was equipped with an AE detector (Model AE-904D AE sensor, Model AE-912 preamplifier, and Model AT-932 discriminator/counter; NF Electronic Instruments). Thermal contraction of the specimen was measured using a nonloading-type dilatometer, connecting alumina rod on the specimen and a differential transformer.

The specimens were prepared to use hydrolysates of alkoxides and to sinter them at $1600^{\circ} \mathrm{C}$. The specimen used in this experiment was $60 \mathrm{~A}\left(\mathrm{Al}_{2} \mathrm{O}_{3}: 60\right.$ mass\%) sintered body with the shape of about $4 \times 4 \times 33 \mathrm{~mm}$, which had the highest content of glass phase among the specimens tested in the previous work. ${ }^{5)}$ The specimen was polished by SiC abrasive paper of \#1000 and set vertically on the sample stage in the electric furnace. The reheating treatment was conducted at $1500^{\circ} \mathrm{C}$ for $4 \mathrm{~h}$ and then the furnace was cooled at the rate of $6{ }^{\circ} \mathrm{C} / \mathrm{min}$. The $\mathrm{AE}$ and the thermal contraction during cooling were measured simultaneously.

\subsection{Lattice parameter of cristobalite}

Cristobalite crystals restrained by mullite grains in ceramics were strained after cooling because of a thermal stress provided with the difference of thermal expansion coefficient between cristobalite and mullite and the volume change during the $\beta-\alpha$ phase transition of cristobalite. The strain was evaluated to compare lattice parameters of reheated cristobalite specimens with standard values. The lattice parameters were measured by XRD method using as-bodies, in order to avoid the release of strain by pulverization. Specimens having silica excess compositions of $60 \mathrm{~A}, 64 \mathrm{~A}$ and $68 \mathrm{~A}$, were sintered at $1600^{\circ} \mathrm{C}$ for $2 \mathrm{~h}$ and reheated at $1500^{\circ} \mathrm{C}$ for $96 \mathrm{~h}$ as described in the previous paper. ${ }^{5)}$ The sample for XRD measurement was prepared by setting the specimen with silicon powder in a special holder. The silicon powder was used as a standard material.

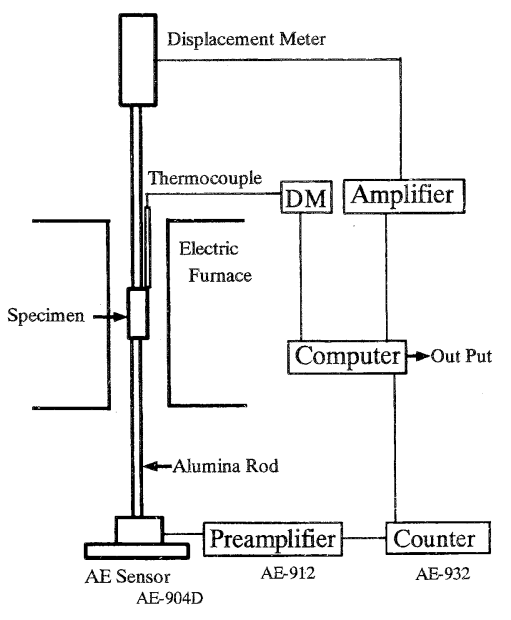

Fig. 2. Schematic illustration of $\mathrm{AE}$ apparatus.

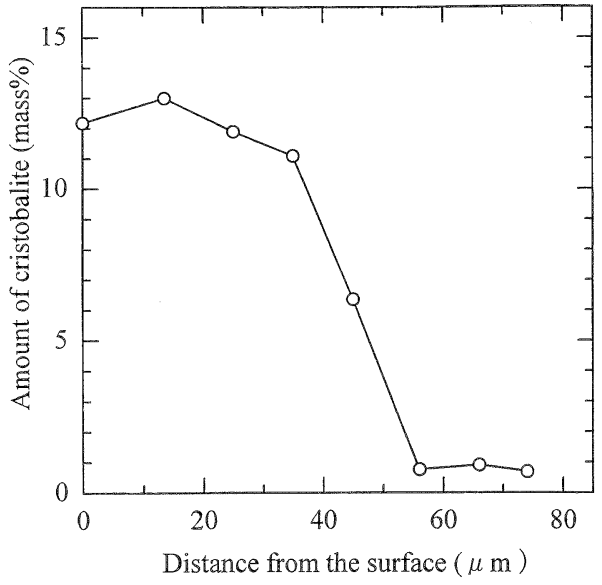

Fig. 3. Change of cristobalite with the distance from the surface of $60 \mathrm{~A}$-specimen reheated at $1500^{\circ} \mathrm{C}$ for $4 \mathrm{~h}$.

The XRD measurement was conducted using (200) and (101) reflections of cristobalite, under conditions of $\mathrm{Cu} \mathrm{Ka}$ line, voltage: $45 \mathrm{kV}$, current: $150 \mathrm{~mA}$, and the speed of goniometer: $1 / 8^{\circ} / \mathrm{min}$.

\subsection{Content of cristobalite}

It is necessary to know the content of constituent phases in order to evaluate the thermal expansion coefficient of a composite material. As the glass phase in the specimens sintered at $1600^{\circ} \mathrm{C}$ is very siliceous, the mullite content should not change in specimens before and after reheating treatment and can be calculated from the starting chemical compositions. The content of cristobalite in reheated specimens was measured by XRD, comparing (101) peak of cristobalite with (200) peak of mullite as an internal standard. The measurement was conducted on the surface of specimen and the ground surface about every $10 \mu \mathrm{m}$, and the results were reported in the previous paper. ${ }^{5)}$ In this work, the values in the specimen 60 A reheated for $4 \mathrm{~h}$ were used and shown in Fig. 3. The content of glass phase was calculated as a residual quantity subtracting the contents of mullite and cristobalite.

\section{Results and discussion}

Figure 4 shows the results of $\mathrm{AE}$ count rate and thermal contraction curve for the specimen 60 A during the cooling after reheating at $1500^{\circ} \mathrm{C}$ for $4 \mathrm{~h}$. The $\mathrm{AE}$ signals were detected below $750^{\circ} \mathrm{C}$. The maximum was around $680^{\circ} \mathrm{C}$ and many signals were also counted below $250^{\circ} \mathrm{C}$. The results indicate that the cracks have been formed in the two different stages during the cooling. The first stage corresponds to the temperature range of $750-650^{\circ} \mathrm{C}$, which is much higher than the $\beta-\alpha$ phase transition temperature for cristobalite, and the second stage takes place below $250^{\circ} \mathrm{C}$ adjusting the phase transition temperature of cristobalite. The high count rate at $750-650^{\circ} \mathrm{C}$ suggested the occurrence of relatively large cracks in a moment.

The thermal contraction curve showed a complex profile but almost linear shrinkage about $0.6 \%$ in all. Figure 5 illustrates the calculated mean thermal contraction curves of mullite ${ }^{8)}$ and cristobalite, ${ }^{9)}$ fixing the basis at the point of $1500^{\circ} \mathrm{C}$. Mullite has a monotonous contraction curve and a linear shrinkage of about $0.8 \%$, while cristobalite keeps to be nearly constant to the phase transition and contracts abruptly, at the phase transition temperature. The measured shrinkage of $0.6 \%$ in Fig. 4 is smaller than that of mullite alone. The small value of shrinkage implies that the occurrence of cracks suppressed the contraction of speci- 
men. The contraction curve in Fig. 4, however, did not show a clear indication of crack formation.

The above results indicate that the cracking at the first stage of high temperature range, $750-650^{\circ} \mathrm{C}$, is based on a mismatch of thermal expansion coefficient between the construction layers in the specimen, that is, the outside layer composed of mullite-cristbalite and the inside layer of mullite-glass. The cracks existing in the specimen, as shown in Fig. 1, are of two kinds, of which the one is parallel to the surface at the boundary between cristobalite crystallization region (outside layer) and glass phase region (inside layer) and the other is perpendicular to the surface of specimen. The cracks based on a mismatch of thermal

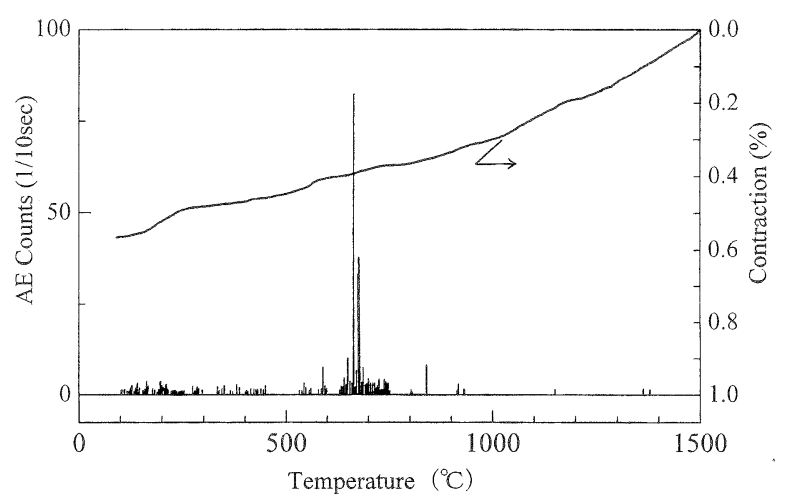

Fig. 4. AE count rate and thermal contraction during cooling.

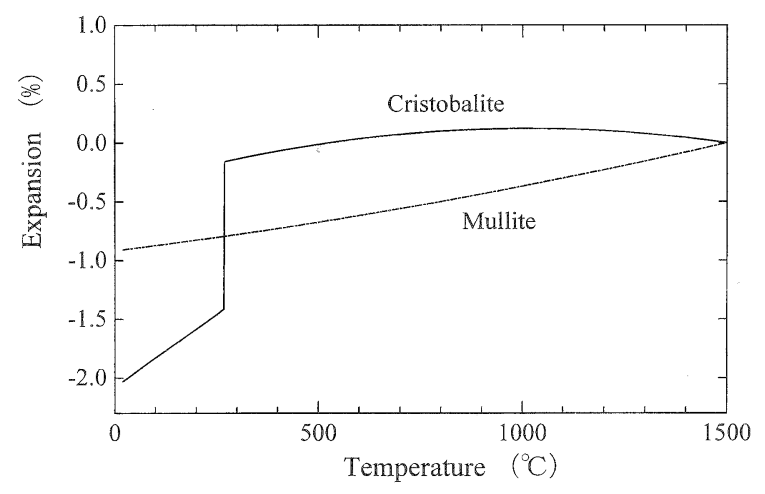

Fig. 5. Thermal contraction of mullite and cristobalite. expansion coefficient between the phase layers must be parallel to the surface of specimen, not to be perpendicular to the surface.

It is necessary to evaluate the thermal expansion coefficient to each composite material, in order to consider the thermal stress occurring between the composite materials composed of plural phases. The thermal expansion coefficients of the outside layer and the inside layer of specimen were calculated from the following equation for composites proposed by Turner: ${ }^{10)}$

$$
\alpha_{\gamma}=\frac{\frac{\alpha_{1} P_{1} K_{1}}{d_{1}}+\frac{\alpha_{2} P_{2} K_{2}}{d_{2}}+\cdots+\frac{\alpha_{n} P_{n} K_{n}}{d_{n}}}{\frac{P_{1} K_{1}}{d_{1}}+\frac{P_{2} K_{2}}{d_{2}}+\cdots+\frac{P_{n} K_{n}}{d_{n}}}
$$

where $\alpha=$ coefficient of linear thermal expansion, $K=$ bulk modulus $=1 /$ bulk compressibility, $d=$ density, $1,2, \ldots n$; constituent phase, $P=$ fraction or percent by mass.

Various parameters used in the calculations are listed in Table 1. Young's modulus of cristobalite was presupposed to be $100 \mathrm{GPa}$, referring the value of $\beta$-quartz. ${ }^{11)}$ Figure 6 shows thermal contraction curves of the outside and inside layers of the specimen $60 \mathrm{~A}$ reheated for $4 \mathrm{~h}$, and also the curve indicating the difference between them. Based on an expression of the thermal expansion coefficient, the maximum value of the thermal contraction curve for the outside layer subtracting that of the inside layer is observed on the difference curve at $750-650^{\circ} \mathrm{C}$. That is, at that temperature range the outside layer is subjected to a large compressive stress and the inside layer undergone a tensile stress. As ceramics are generally weaker under a tensile stress than a compressive stress, cracking should occur under a tensile stress. Certainly, the position of cracks parallel to the surface of specimen is in the inside layer under a tensile stress. Drory et al. ${ }^{13)}$ discussed the position of cracking, using a finite element method applied to the specimen, the outside layer of which is subjected to a compressive stress, and indicated that the cracking happens at the position to some degree within the boundary between a compressible stress layer of the outside and a tensile stress layer of the inner part, namely, at the position where the stress intensity factor of mode II, $K_{\mathrm{II}}$, becomes to be zero in the specimen. The result of their analysis strongly supports the cracking behavior occurring parallel to the surface of specimen.

The cracks forming at the second stage at $250^{\circ} \mathrm{C}$ are thought to be related to the phenomenon of the $\beta-\alpha$ phase

Table 1. Data Used for the Calculation by Turner's Equation

\begin{tabular}{|c|c|c|c|c|}
\hline & \multirow[t]{2}{*}{ Mullite ${ }^{8)}$} & \multicolumn{2}{|c|}{ Cristobalite ${ }^{9), 11)}$} & \multirow[t]{2}{*}{ Sillica Glass ${ }^{12}$} \\
\hline & & Low & High & \\
\hline $\mathrm{X}_{1}^{*}$ & 4.24 & 25.15 & 10.36 & 0.55 \\
\hline $\mathrm{X}_{2}^{*}$ & 1.29 & 0 & -5.12 & 0 \\
\hline Young's modulus (GPa) & 220 & \multicolumn{2}{|c|}{100} & 73 \\
\hline $\operatorname{Density}\left(\times 10^{3} \mathrm{~kg} / \mathrm{m}^{3}\right)$ & 3.17 & \multicolumn{2}{|c|}{2.33} & 2.20 \\
\hline Outside layer & 83.5 & \multicolumn{2}{|c|}{13.0} & 3.4 \\
\hline Inside layer & 83.5 & \multicolumn{2}{|c|}{0} & 16.4 \\
\hline
\end{tabular}




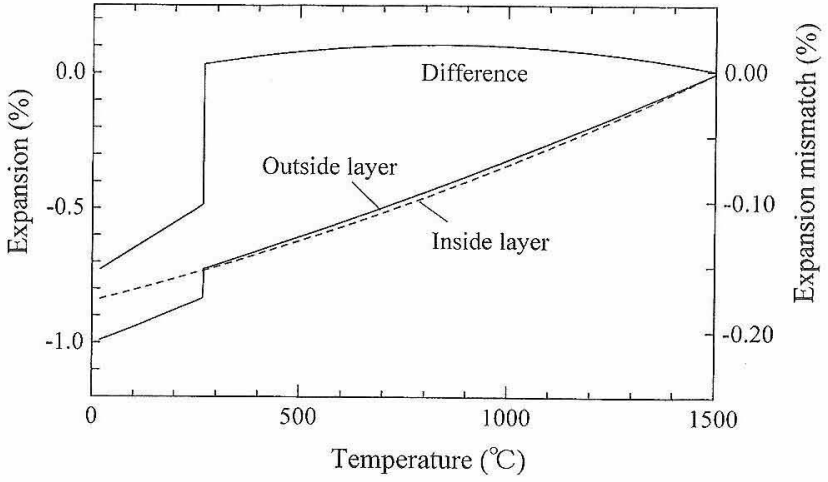

Fig. 6. Thermal contraction and mismatch of outside layer and inside layer.

transition of cristobalite generating a large volume contraction. Figure 5 suggests that cristobalite restrained by mullite grains in ceramics is subjected to the compressive stress above the phase transition temperature and to the tensile stress below that temperature. Their stresses can be detected as a strain of cristobalite lattices. Lattice parameters of cristobalite at room temperature in the specimens reheated for $96 \mathrm{~h}$, having no cracks, are shown in Fig. 7. The values are almost constant among the specimens. Nevertheless, the values of $a$-axis and $c$-axis are about $0.8 \%$ and $2.2 \%$ longer than those of the standard $\left(a_{0}=0.49732 \mathrm{~nm}, c_{0}=0.69236 \mathrm{~nm}\right),{ }^{14)}$ respectively. The results indicate that cristobalite in the specimens is subjected to a tensile stress. The shrinkages of $a$-axis and $c$-axis of cristbalite alone between $1500^{\circ} \mathrm{C}$ and room temperature are $1.57 \%$ and $3.09 \%$, respectively, while the mean linear shrinkage of mullite is $0.93 \%$. As cristobalite crystals are restrained by mullite grains, the actual constraction value of cristobalite in the specimen should be the same as that of mullite, because mullite is a main constituent phase in the specimens and has a much higher Young's modulus than cristobalite. The differences of the shrinkage values of cristobalite subtracting mullite are $0.64 \%$ for $a$-axis and $2.16 \%$ for $c$-axis, respectively, and correspond to the strain values of cristobalite at room temperature. They are practically equal to the measurement result of lattice parameters of cristobalite. Cristobalite in the specimens at the middle stage of crystallization should also be subjected to a tensile stress.

The tensile stress to which crystallized cristobalite is subjected acts to contract the outside layer of specimen rather than the inside layer below the transiton temperature of cristobalite, as shown in Fig. 6. As a result, the outside layer is subjected to a tensile stress in the parallel to the surface direction, and the stress causes cracks perpendicular to the direction of tensile stress, i.e., to the surface of specimen. The change from a compressive stress to a tensile stress of the outside layer due to the $\beta-\alpha$ phase transition of cristobalite also should cause extending the cracks already existing.

The cracking mechanism in this work was modeled and the scheme was shown in Fig. 8. During cooling process at the temperature range of $1500-250^{\circ} \mathrm{C}$ (a), the outside layer where cristobalite crystallizes is subjected to a compressive stress and the inside layer to a tensile stress. These stresses reach maximum around $750-650^{\circ} \mathrm{C}$ and cause cracks parallel to the surface of specimen at the position within the boundary between the outside layer and the inner part. At the temperature range below $250^{\circ} \mathrm{C}$ (b), the $\beta-\alpha$ phase transition of cristobalite generates a large volume contraction, and the outside layer changes to a tensile stress in the

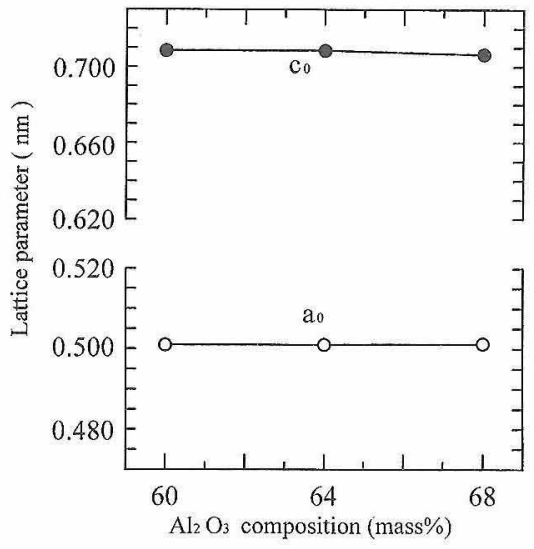

Fig. 7. Lattice parameter of cristobalite in specimens reheated at $1500{ }^{\circ} \mathrm{C}$ for $96 \mathrm{~h}$.

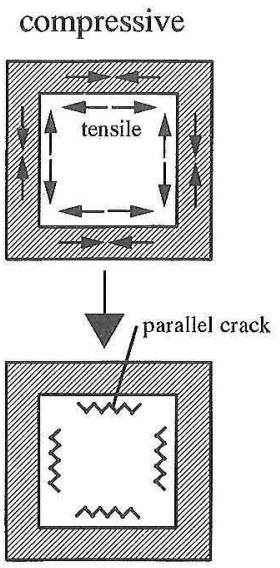

(a) $1500^{\circ} \mathrm{C} \sim 250^{\circ} \mathrm{C}$ tensile

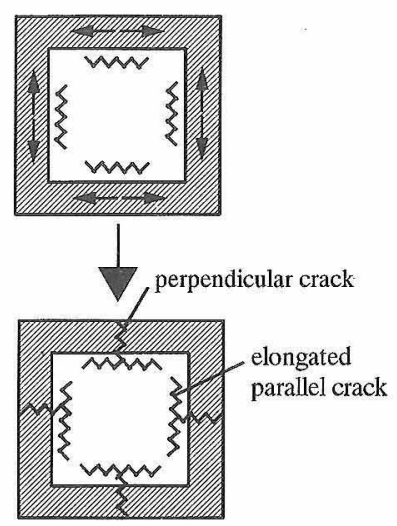

(b) $250^{\circ} \mathrm{C} \sim \mathrm{R} . \mathrm{T}$.
Fig. 8. Schematic illustration for mechanism of crack formation.

parallel to the surface direction. The tensile stress causes cracking perpendicular to the surface of specimen.

\section{Conclusions}

Cracking of a cristobalite-containing mullite body during cooling was investigated by $\mathrm{AE}$ and the origin was discussed.

(1) Cracks were classified into two groups, of which the one is parallel to the surface of specimen within of the boundary between the outside layer and the inside layer, and the other is perpendicular to the surface.

(2) The signals of $\mathrm{AE}$ indicated that cracks were generated in the two stages, the first stage at the temperature range of $750-650^{\circ} \mathrm{C}$ and the second stage below $250^{\circ} \mathrm{C}$.

(3) The cracks parallel to the surface of specimen occurred at the temperature range of $750-650^{\circ} \mathrm{C}$ due to a mismatch of thermal expansion coefficient between the outside layer and the inside layer. The cracks perpendicular to the surface were formed below $250^{\circ} \mathrm{C}$ under a tensile stress of the outside layer which was caused by $\beta-\alpha$ phase transition of cristobalite, in the parallel direction to the surface.

Acknowledgement The authors wish to thank Dr. Yury Dm. Litasov of research fellow of Faculty of Engineering and Resource Science, Akita University, and United Institute of Geology, Geophysics, and Mineralogy Siberian Branch, Russian Academy of Science for helpful discussion and critical reading of the 
manuscript.

\section{References}

1) P. C. Dokko, J. A. Pask and K. S. Mazdiyasni, J. Am. Ceram. Soc., 60, 150-55 (1977).

2) M. D. Sacks and J. A. Pask, J. Am. Ceram. Soc., 65, 65-70 (1982).

3) T. Kawanami, "Shinsozai Series Mullite I," Ed. by S. Sömiya, Uchida Rokakuho (1985) pp. 123-35 [in Japanese].

4) T. Kumazawa, S. Kanzaki. S. Ohta and H. Tabata, J. Ceram. Soc. Japan (Seramikkusu Ronbunshi), 96, 85-91 (1988) [in Japanese].

5) T. Sato, Y. Sawabe, Y. Ohya, M. Sugai and Z. Nakagawa, J. Ceram. Soc. Japan, 107, 838-43 (1999) [in Japanese].
6) A. B. Thompson and M. Wennemer, Am. Mineral., 64, 1018-26 (1979).

7) Y. Ohya, Y. Takahashi, M. Murata, Z. Nakagawa and K. Hamano, J. Am. Ceram. Soc., 82, 445-48 (1999).

8) D. Taylor, Br. Ceram. Trans. J., 86, 1-6 (1987)

9) D. Taylor, Br. Ceram. Trans. J., 83, 129-33 (1984).

10) P. S. Turner, J. Res. NBS, 37, 239-50 (1946).

11) "Kagakubinran," Ed. Chemical Society of Japan, Maruzen (1984) p. II-34 [in Japanese].

12) B. Bridge, N. D. Patel and D. N. Waters, Phys. Stat. Sol., 77, 655-68 (1983).

13) M. D. Drory, M. D. Thouless and A. G. Evans, Acta Metall., 36, 2019-28 (1988).

14) JCPDS Cards, No. 39-1425. 